\title{
Analisis Fasa, Struktur Kristal dan Sifat Kemagnetan Material Komposit Berbasis $\mathrm{Nd}_{0,6} \mathrm{Sr}_{0,4} \mathrm{MnO}_{3} / \mathrm{Fe}_{2} \mathrm{O}_{3}$
}

\author{
Mujadid Al-Rabi ${ }^{1, \uparrow}$, Arif Tjahjono ${ }^{2}$, dan Sitti Ahmiatri Saptari ${ }^{3}$
}

\begin{abstract}
${ }^{1}$ Program Studi Fisika, Fakultas Sains dan Teknologi, Universitas Islam Negeri Syarif Hidayatullah Jakarta, Jalan. Ir. H. Djuanda No.95, Cempaka Putih, Ciputat, Kota Tangerang Selatan, Banten 15412, Indonesia

${ }^{2}$ Program Studi Fisika, Fakultas Sains dan Teknologi, Universitas Islam Negeri Syarif Hidayatullah Jakarta, Jalan. Ir. H. Djuanda No.95, Cempaka Putih, Ciputat, Kota Tangerang Selatan, Banten 15412, Indonesia
\end{abstract}

${ }^{3}$ Program Studi Fisika, Fakultas Sains dan Teknologi, Universitas Islam Negeri Syarif Hidayatullah Jakarta, Jalan. Ir. H. Djuanda No.95, Cempaka Putih, Ciputat, Kota Tangerang Selatan, Banten 15412, Indonesia

\section{†mujadidalrabi@gmail.com}

\begin{abstract}
Abstrak. Pada penelitian ini dipelajari rekayasa struktur material komposit berbasis neodymium manganit, yang dimulai dengan mensintesis material $\mathrm{Nd}_{0,6} \mathrm{Sr}_{0,4} \mathrm{MnO}_{3}$ (NSMO) dengan menggunakan metode sol-gel, lalu dilanjutkan dengan sintesis material komposit $\left(\mathrm{Nd}_{0,6} \mathrm{Sr}_{0,4} \mathrm{MnO}_{3}\right)_{1-\mathrm{x}} /\left(\mathrm{Fe}_{2} \mathrm{O}_{3}\right)_{\mathrm{x}}$ dengan persentase berat ( $x=0 ; 0,3 ; 0,5$ dan 0,7). Hasil pengujian $X$-Ray Diffraction menunjukkan bahwa sampel NSMO memiliki struktur kristal orthorombik dengan space group P n m a. Setelah dikompositkan dengan $\mathrm{Fe}_{2} \mathrm{O}_{3}$, tidak ada perubahan struktur yang terjadi tetapi muncul fasa lain yang ditandai dengan adanya puncak difraksi milik $\mathrm{Fe}_{2} \mathrm{O}_{3}$. Hasil pengujian Field Emission Scanning Electron Microscope menunjukkan persebaran butir yang merata dengan ukuran butir rata-rata 0,186 $\mu \mathrm{m}$. Hasil pengujian Vibrating Sample Magnetometer pada temperatur ruang $(298 \mathrm{~K})$ dengan medan magnet $2 \mathrm{~T}$, menunjukkan material komposit NSMO / $\mathrm{Fe}_{2} \mathrm{O}_{3}$ bersifat paramagnetik dan nilai magnetisasi serta susceptibilitas sampel semakin menurun seiring dengan penambahan konsentrasi $\mathrm{Fe}_{2} \mathrm{O}_{3}$.
\end{abstract}

Kata Kunci: Komposit, magnetisasi, NSMO, sol-gel, susceptibility.

\begin{abstract}
In this study, the structural engineering of composite materials based on neodymium manganite was studied, starting with synthesizing the $\mathrm{Nd}_{0,6} \mathrm{Sr}_{0,4} \mathrm{MnO}_{3}$ (NSMO) material using the sol-gel method, then continued with the synthesis of composite materials $\left(\mathrm{Nd}_{0,6} \mathrm{Sr}_{0,4} \mathrm{MnO}_{3}\right)_{1-\mathrm{x}} /\left(\mathrm{Fe}_{2} \mathrm{O}_{3}\right)_{\mathrm{x}}$ with percentage by weight ( $x=0 ; 0,3 ; 0,5$ and 0,7$)$. The X-Ray Diffraction test results show that the NSMO sample has an orthorombic crystal structure with a space group of $\mathrm{P} \mathrm{n} \mathrm{m} \mathrm{a.} \mathrm{After} \mathrm{being} \mathrm{composited} \mathrm{with} \mathrm{Fe}_{2} \mathrm{O}_{3}$, no structural changes occurred but another phase appeared which was marked by the presence of $\mathrm{Fe}_{2} \mathrm{O}_{3}$ diffraction peaks. Field Emission Scanning Electron Microscope test results showed an even grain distribution with an average grain size of $0,186 \mu \mathrm{m}$. The results of the Vibrating Sample Magnetometer test at room temperature $(298 \mathrm{~K})$ with a $2 \mathrm{~T}$ magnetic field, showed that the $\mathrm{NSMO} / \mathrm{Fe}_{2} \mathrm{O}_{3}$ composite material was paramagnetic and the magnetization value and sample susceptibility decreased along with the addition of $\mathrm{Fe}_{2} \mathrm{O}_{3}$ concentration.
\end{abstract}

Keywords: Composite, magnetization, NSMO, sol-gel, susceptibility.

DOI : $10.15408 /$ fiziya.v3i2.17638 


\section{PENDAHULUAN}

Material perovskite manganit telah menjadi perhatian luas dikalangan peneliti hingga saat ini, dengan rumus umum $\mathrm{RE}_{1-x} \mathrm{~A}_{x} \mathrm{MnO}_{3}$, dimana $\mathrm{RE}$ mewakili ion tanah jarang seperti $\mathrm{La}^{3+}$, $\mathrm{Nd}^{3+}, \mathrm{Pr}^{3+}$, dan A mewakili ion divalent seperti $\mathrm{Sr}^{2+}, \mathrm{Ba}^{2+}, \mathrm{Ca}^{2+}$. Doping yang dilakukan pada material perovskite manganit akan menimbulkan berbagai fenomena menarik seperti Colossal Magnetoresistance (CMR) dan Magnetocaloric effect (MCE) [1][2].

Perovskite manganit memiliki beberapa potensi untuk digunakan sebagai media penyimpan magnetik, sensor magnetik, absorber, thin film, dan lain-lain [3][4][5]. Sistem ini dipelajari secara luas dan ekstensif sekitar 40 tahun yang lalu mengenai efek crystal-field dan kopling Hund, interaksi superexchange dan double-exchange, serta efek Jahn-Teller [6].

Saat ini, sebagian besar penelitian berfokus pada doping divalent logam alkali tanah di dalam senyawa $\mathrm{RE}_{1-\mathrm{x}} \mathrm{A}_{\mathrm{x}} \mathrm{MnO}_{3}$, maupun dengan penambahan bahan lain untuk merekayasa sifat material dari senyawa $\mathrm{RE}_{1-\mathrm{x}} \mathrm{A}_{\mathrm{x}} \mathrm{MnO}_{3}$ tersebut. Pada penelitian yang dilakukan oleh M. Naomi dkk [7] terhadap sifat magnetik material $\mathrm{Nd}_{1-\mathrm{x}} \mathrm{Sr}_{\mathrm{x}} \mathrm{MnO}_{3}$ menyimpulkan bahwa pada $x=0,4$ menunjukkan sifat feromagnetik hingga terjadi peralihan menuju paramagnetik pada temperatur curie $\left(T_{\mathrm{c}}\right) 244 \mathrm{~K}$.

Ahmed dkk [8] dalam penelitian yang dilakukannya dengan mengkompositkan material $\mathrm{Nd}_{0,6} \mathrm{Sr}_{0,4} \mathrm{MnO}_{3}$ dengan senyawa $\mathrm{CrO}_{3}$, menyatakan bahwa penambahan senyawa $\mathrm{CrO}_{3}$ pada NSMO memperbesar nilai resistivitas dan mengurangi Transisi Metal-Insulator ( $\left.T_{\mathrm{MI}}\right)$. Pengukuran nilai magnetisasi menunjukkan hampir tidak adanya perubahan pada temperatur currie $\left(T_{\mathrm{c}}\right)$, meskipun saat telah dihilangkan momen magnetnya. Disebutkan pula bahwa proses komposit material dapat menurunkan interaksi double exchange (DE) yang akan menurunkan sifat kemagnetannya. Penelitian yang dilakukan oleh Balaraju dkk [9] terhadap sifat magnetik menyimpulkan bahwa nanopartikel $\alpha-\mathrm{Fe}_{2} \mathrm{O}_{3}$ yang diukur dengan VSM pada temperatur $100 \mathrm{~K}$ dengan medan magnet eksternal $-10 \mathrm{kOe}$ to $+10 \mathrm{kOe}$ menunjukkan sifat feromagnetik.

Penelitian ini dilakukan untuk mengkaji struktur kristal dan sifat kemagnetan pada material $\mathrm{Nd}_{0,6} \mathrm{Sr}_{0,4} \mathrm{MnO}_{3}$ (NSMO) yang akan dikompositkan dengan prekursor $\mathrm{Fe}_{2} \mathrm{O}_{3}$. Dimana berdasarkan karakteristik yang dimiliki oleh $\mathrm{Fe}_{2} \mathrm{O}_{3}$ yang merupakan feromagnetik, diharapkan dapat meningkatkan sifat kemagnetan pada material kamposit yang dihasilkan. Material komposit $\left(\mathrm{Nd}_{0,6} \mathrm{Sr}_{0,4} \mathrm{MnO}_{3}\right)_{1-\mathrm{x}} /\left(\mathrm{Fe}_{2} \mathrm{O}_{3}\right)_{\mathrm{x}}$ dibuat dengan variasi persentase berat $x=0 ; 0,3 ; 0,5$; dan 0,7. Proses sintesis yang digunakan untuk pembuatan sampel NSMO pada penelitian ini adalah dengan menggunakan metode sol-gel, kemudian dilanjutkan pengkompositan dengan prekursor $\mathrm{Fe}_{2} \mathrm{O}_{3}$ melalui proses stiring dengan menggunakan medium ethanol. Sampel yang telah selesai, dikarakterisasi dengan menggunakan X-Ray Diffraction (XRD) untuk mengetahui fasa, struktur kristal dan paramaternya, kemudian dikarakterisasi Field Emission Scanning Electron Microscope (FESEM) untuk mengetahui morfologi sampel, serta karakterisasi Vibrating Sample Magnetometer (VSM) untuk mengetahui sifat kemagnetan sampel.

\section{METODE}

Pembuatan material $\left(\mathrm{Nd}_{0,6} \mathrm{Sr}_{0,4} \mathrm{MnO}_{3}\right)_{1-\mathrm{x}} /\left(\mathrm{Fe}_{2} \mathrm{O}_{3}\right)_{\mathrm{x}}$ diawali dengan mensintesis material $\mathrm{Nd}_{0,6} \mathrm{Sr}_{0,4} \mathrm{MnO}_{3}$ menggunakan metode sol-gel. Prekursor yang digunakan yaitu $\mathrm{Nd}_{2} \mathrm{O}_{3}, \mathrm{Sr}\left(\mathrm{NO}_{3}\right)_{2}$, $\mathrm{Mn}\left(\mathrm{NO}_{3}\right)_{2} .4 \mathrm{H}_{2} \mathrm{O}$ dan $\mathrm{C}_{6} \mathrm{H}_{8} \mathrm{O}_{7} \cdot \mathrm{H}_{2} \mathrm{O}$ dari bahan pro analysis dari Merck, Jerman, dengan masingmasing kemurnian 99,9\%, 99\%, 98.5\% dan 99,5\%, serta prekursor $\mathrm{Fe}_{2} \mathrm{O}_{3}$ dari Sigma-Aldrich, India dengan kemurnian 99,98\%. Prekursor $\mathrm{Sr}\left(\mathrm{NO}_{3}\right)_{2}, \mathrm{Mn}\left(\mathrm{NO}_{3}\right)_{2} \cdot 4 \mathrm{H}_{2} \mathrm{O}$ dan $\mathrm{C}_{6} \mathrm{H}_{8} \mathrm{O}_{7} \cdot \mathrm{H}_{2} \mathrm{O}$ dilarutkan dengan menggunakan aquabidest, dan $\mathrm{Nd}_{2} \mathrm{O}_{3}$ ditambahkan dengan asam nitrat $\left(\mathrm{HNO}_{3}\right)$ hingga menjadi basis nitrat $\left(\mathrm{Nd}_{2}\left(\mathrm{NO}_{3}\right)_{2}\right)$ yang ditandai dengan larutan berubah bening, kemudian dilanjutkan dengan mencampurnya dengan semua prekursor yang telah dilarutkan. Campuran prekursor kemudian diaduk dan dipanaskan hingga $80^{\circ} \mathrm{C}$ di atas hot plate magnetik dan ditambahkan larutan ammonia hingga $\mathrm{pH}$ 7. Setelah campuran menggumpal membentuk wujud gel, sampel didehidrasi pada suhu $150^{\circ} \mathrm{C}$ selama 2 jam untuk menghilangkan kandungan air. Setelah itu dilakukan proses pra kalsinasi pada temperatur $600^{\circ} \mathrm{C}$ ditahan selama 6 jam dan kalsinasi $900^{\circ} \mathrm{C}$ ditahan selama 12 jam. 
Karakterisasi sampel menggunakan X-Ray Diffraction (XRD) untuk mengamati fase yang terbentuk. Selanjutnya mengkompositkan sampel NSMO dengan prekursor $\mathrm{Fe}_{2} \mathrm{O}_{3}$ dengan cara mencampurkan dan mengaduk larutan tersebut dalam medium ethanol selama 30 menit hingga homogen. Kemudian dilakukan dehidrasi sampel pada temperatur $100^{\circ} \mathrm{C}$ selama 1 jam sampai seluruh ethanol menguap. Dilakukan pengujian selanjutnya yaitu analisis morfologi dan ukuran butir menggunakan Field Emission Scanning Electron Microscope (FESEM) dan dilanjutkan dengan pengujian sifat kemagnetan menggunakan Vibrating Sample Magnetometer (VSM).

Dari nilai magnetisasi yang diperoleh dari pengujian VSM dapat dilakukan perhitungan untuk mendapatkan nilai susceptibility $(\chi)$, yaitu tingkat kerentanan atau kepekaan suatu material untuk termagnetisasi. Besarnya nilai susceptibility $(\chi)$ sampel dapat dihitung melalui rasio dari nilai magnetisasi dengan medan magnet seperti pada persamaan 1 [10].

Dimana:

$$
\chi=\frac{M}{H}
$$

$$
\begin{aligned}
& \chi=\text { Nilai } \text { susceptibility }(\mathrm{emu} / \mathrm{g} . \mathrm{T}) \\
& M=\text { Nilai magnetisasi }(\mathrm{emu} / \mathrm{g}) \\
& H=\text { Nilai medan magnet }(\mathrm{T})
\end{aligned}
$$

\section{HASIL DAN DISKUSI}

\section{Karakterisasi XRD}

Sampel NSMO dan $(\mathrm{NSMO})_{0,5} /\left(\mathrm{Fe}_{2} \mathrm{O}_{3}\right)_{0,5}$ dikarakterisasi menggunakan XRD untuk mengetahui fasa, struktur kristal dan parameter kisi sampel. Hasil karakterisasi XRD terhadap sampel menghasilkan pola difraksi yang menunjukkan adanya fasa lain milik $\mathrm{Fe}_{2} \mathrm{O}_{3}$ setelah dikompositkan terhadap sampel NSMO seperti yang ditampilkan pada Gambar 1. Kemudian dilakukan analisis hasil XRD dengan menggunakan metode rietvield refinement untuk mengetahui lebih lanjut informasi dari sampel yang telah dikarakterisasi XRD dengan menggunakan software HighScore Plus [11][12].

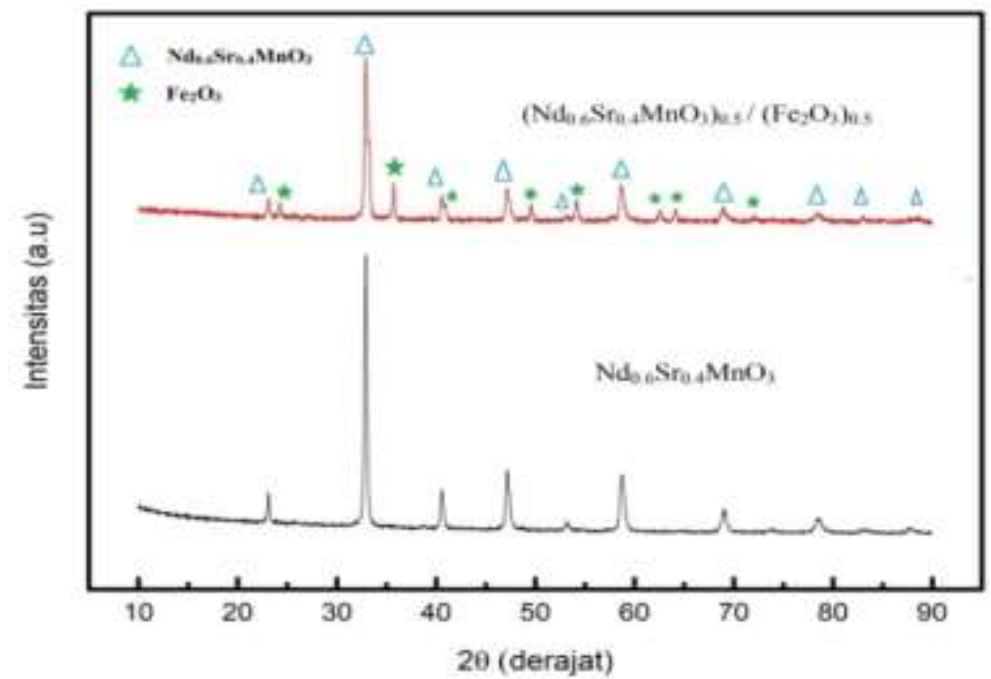

Gambar 1. Pola XRD pada material NSMO dan (NSMO) $)_{0,5} /\left(\mathrm{Fe}_{2} \mathrm{O}_{3}\right)_{0,5}$

Gambar 2. menunjukkan profil XRD dari penelitian yang dilakukan oleh Balaraju dkk [9] terhadap serbuk $\alpha-\mathrm{Fe}_{2} \mathrm{O}_{3}$ yang diproduksi oleh Sigma-Aldrich. Gambar 3. menunjukkan hasil pengolahan data XRD sampel NSMO menggunakan database ICSD 98-015-7631 [13], dimana didapatkan nilai chi-square $\left(\chi^{2}\right)$ sebesar 1,08 yang menandakan bahwa hasil refinement yang dilakukan memiliki kecocokan yang baik dengan database yang digunakan. Analisa ini diperkuat menurut Erfan Handoko dkk [14] yang menyatakan bahwa hasil refinement yang baik memiliki nilai chi-square dalam rentang 1-1,5. Dari hasil refinement menunjukkan bahwa sampel memiliki fasa tunggal dengan tidak adanya fasa pengotor. 


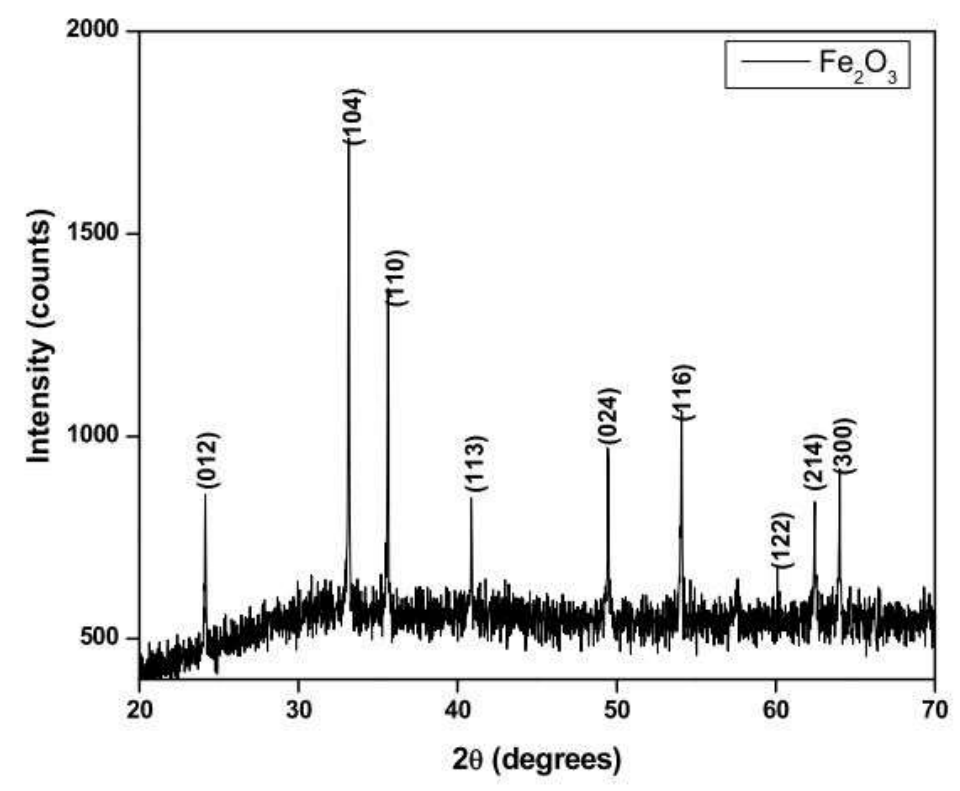

Gambar 2. Profil XRD $\alpha-\mathrm{Fe}_{2} \mathrm{O}_{3}[9]$.

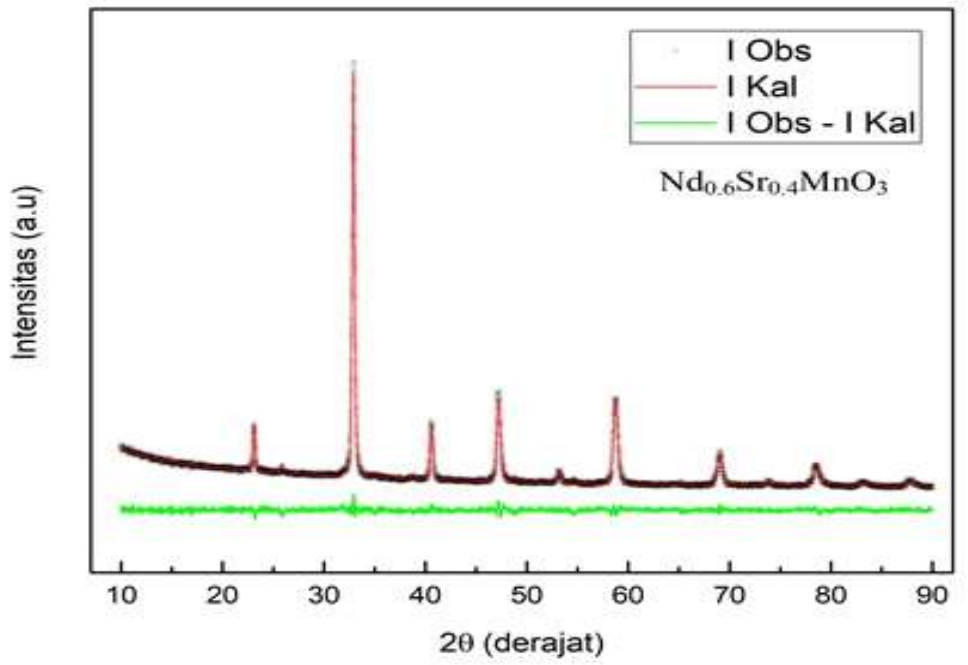

Gambar 3. Pola XRD pada NSMO setelah dilakukan rietvield refinement.

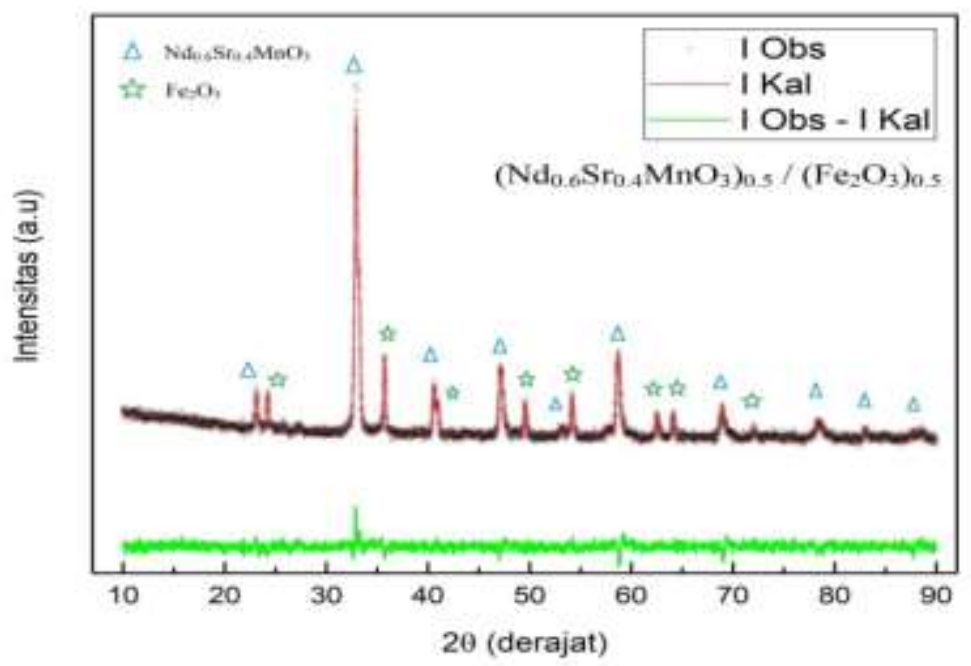

Gambar 4. Pola XRD pada $(\mathrm{NSMO})_{0,5} /\left(\mathrm{Fe}_{2} \mathrm{O}_{3}\right)_{0,5}$ setelah dilakukan rietvield refinement.

Gambar 4. menunjukkan hasil pengolahan data XRD sampel (NSMO) $)_{0,5} /\left(\mathrm{Fe}_{2} \mathrm{O}_{3}\right)_{0,5}$ menggunakan database ICSD 98-041-5251 [15] dengan nilai chi-square $\left(\chi^{2}\right)$ sebesar 1,03. 
Parameter kisi pada sampel NSMO sebelum dan sesudah dikompositkan dengan $\mathrm{Fe}_{2} \mathrm{O}_{3}$ nilainya tidak berbeda jauh, seperti yang ditampilkan pada Tabel 1. Pada Tabel 1, dapat terlihat nilai bandwith yang diperoleh mengalami penurunan, dikarenakan adanya pertambahan panjang ikatan $(d<\mathrm{Mn}-\mathrm{O}\rangle)$ dan penurunan sudut ikatan $(\theta<\mathrm{Mn}-\mathrm{O}-\mathrm{Mn}>$ setelah sampel dikompositkan. Dimana penurunan nilai bandwith berkaitan erat dengan menurunnya kemampuan double exchange (DE), dan akan mempengaruhi sifat magnetik dan sifat listriknya [16].

Tabel 1. Informasi kristalografi hasil analisis material (NSMO) $)_{0,5} /\left(\mathrm{Fe}_{2} \mathrm{O}_{3}\right)_{0,5}$.

\begin{tabular}{|c|c|c|c|}
\hline \multirow{2}{*}{ Parameter } & \multirow{2}{*}{$\begin{array}{c}x=0 \\
\mathrm{Nd}_{0,6} \mathrm{Sr}_{0,4} \mathrm{MnO}_{3}\end{array}$} & \multicolumn{2}{|l|}{$x=0,5$} \\
\hline & & $\mathrm{Nd}_{0,6} \mathrm{Sr}_{0,4} \mathrm{MnO}_{3}$ & $\mathrm{Fe}_{2} \mathrm{O}_{3}$ \\
\hline Space Group & Pnma & Pnma & $\mathrm{R}-3 \mathrm{c}$ \\
\hline $\mathrm{a}(\AA)$ & 54,423 & 54,563 & 50,368 \\
\hline $\mathrm{b}(\AA)$ & 76,781 & 76,849 & 50,368 \\
\hline $\mathrm{c}(\AA)$ & 54,616 & 54,715 & 137,568 \\
\hline $\mathrm{V}\left(\AA^{3}\right)$ & 228,224 & 229,426 & 302,238 \\
\hline Ukuran kristal rata-rata $(\mathrm{nm})$ & 23 & \multicolumn{2}{|l|}{38} \\
\hline \multicolumn{4}{|c|}{ Disrepancy Factors } \\
\hline $\mathrm{RWP}_{\mathrm{P}}(\%)$ & 4,33 & \multicolumn{2}{|l|}{2,77} \\
\hline $\mathrm{Rp}(\%)$ & 3,34 & \multicolumn{2}{|l|}{2,14} \\
\hline Chi-square $\left(\chi^{2}\right)$ & 1,08 & \multicolumn{2}{|l|}{1,03} \\
\hline \multicolumn{4}{|c|}{ Panjang Ikatan (§̊) } \\
\hline \multirow{2}{*}{$\mathrm{Mn}-\mathrm{O}(1)$} & 1,815 & \multicolumn{2}{|l|}{1,912} \\
\hline & 2,074 & \multicolumn{2}{|l|}{2,029} \\
\hline \multirow{2}{*}{$\mathrm{Mn}-\mathrm{O}(2)$} & 1,946 & \multicolumn{2}{|l|}{1,933} \\
\hline & 1,946 & \multicolumn{2}{|l|}{1,933} \\
\hline$\langle\mathrm{Mn}-\mathrm{O}\rangle$ & 1,945 & \multicolumn{2}{|l|}{1,952} \\
\hline \multicolumn{4}{|c|}{ Sudut Ikatan $\left(^{\circ}\right)$} \\
\hline $\mathrm{Mn}-\mathrm{O}(1)-\mathrm{Mn}$ & 164,672 & \multicolumn{2}{|l|}{157,211} \\
\hline $\mathrm{Mn}-\mathrm{O}(2)-\mathrm{Mn}$ & 161,655 & \multicolumn{2}{|l|}{167,53} \\
\hline$<\mathrm{Mn}-\mathrm{O}-\mathrm{Mn}>$ & 163,16 & \multicolumn{2}{|l|}{162,37} \\
\hline \multicolumn{4}{|c|}{ Bandwidth (u.a) } \\
\hline $\mathrm{W}\left(10^{-2}\right)$ & 9,64 & \multicolumn{2}{|l|}{9,54} \\
\hline \multicolumn{4}{|c|}{ Tolerance Factor } \\
\hline Goldscmidth & \multicolumn{3}{|c|}{0,933} \\
\hline
\end{tabular}




\section{Karakterisasi FESEM}

Morfologi sampel NSMO yang telah dikarakterisasi dengan menggunakan FESEM Pada perbesaran 5.000 kali seperti yang ditampilkan pada Gambar 4 terlihat bahwa sampel memiliki butir yang tersebar secara merata dan memiliki bentuk yang relatif sama, yang menunjukkan homogenitas sampel NSMO. Pada perbesaran 50.000 kali yang ditampilkan pada Gambar 5, ukuran butir yang didapat dari beberapa titik pada sampel yang diuji yaitu sebesar 0,$140 ; 0,200$; 0,$252 ; 0,192 ; 0,188 ; 0,108$ dan $0,224 \mu \mathrm{m}$, sehingga didapatkan nilai ukuran butir rata-rata sampel sebesar $0,186 \mu \mathrm{m}$.

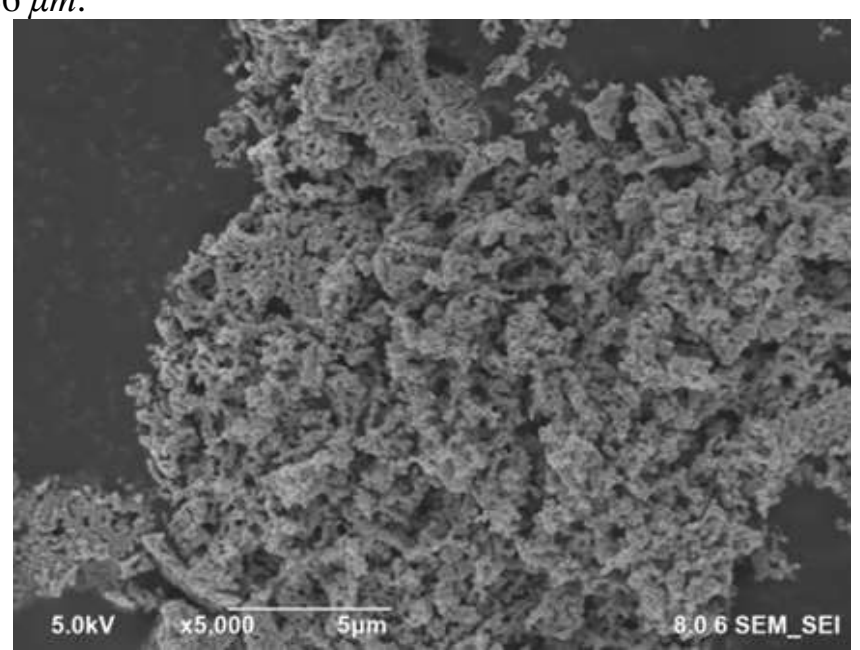

Gambar 4. Hasil karakterisasi FESEM material $\mathrm{Nd}_{0,6} \mathrm{Sr}_{0,4} \mathrm{MnO}_{3}$ dengan perbesaran 5.000 kali.

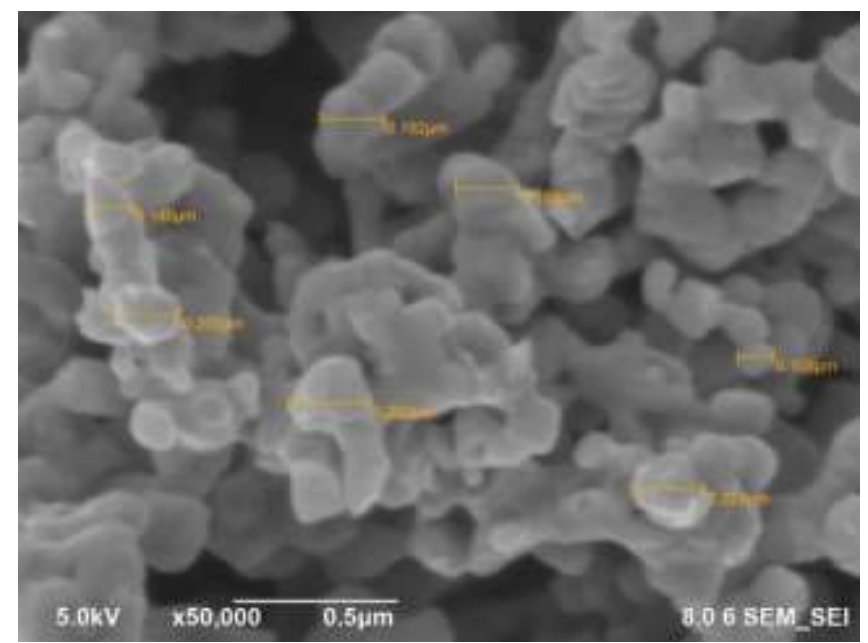

Gambar 5. Hasil karakterisasi FESEM material $\mathrm{Nd}_{0,6} \mathrm{Sr}_{0,4} \mathrm{MnO}_{3}$ dengan perbesaran 50.000 kali.

\section{Karakterisasi VSM}

Karakterisasi VSM dari sampel komposit $\left(\mathrm{Nd}_{0,6} \mathrm{Sr}_{0,4} \mathrm{MnO}_{3}\right)_{1-\mathrm{x}} /\left(\mathrm{Fe}_{2} \mathrm{O}_{3}\right)_{\mathrm{x}}(\mathrm{x}=0,0,3 ; 0,5$; $0,7)$ dilakukan pada temperatur disekitar temperatur ruang $(298 \mathrm{~K})$ dengan medan magnet sebesar $2 \mathrm{~T}$. Kurva histeresis dari sampel material komposit $\left(\mathrm{Nd}_{0,6} \mathrm{Sr}_{0,4} \mathrm{MnO}_{3}\right)_{1-\mathrm{x}} /\left(\mathrm{Fe}_{2} \mathrm{O}_{3}\right)_{\mathrm{x}}$ ditampilkan pada Gambar 6, dan terlihat bahwa sampel memiliki nilai magnetisasi yang kecil, yang menandakan bahwa sampel tersebut merupakan material paramagnetik.

Kurva histerisis pada Gambar 6 menunjukkan bahwa sampel NSMO tanpa komposit memiliki nilai magnetisasi lebih besar yaitu sebesar 5,32 emu/g dibandingkan dengan setelah dikompositkan. Saat material dikompositkan (NSMO) $)_{1-x} /\left(\mathrm{Fe}_{2} \mathrm{O}_{3}\right)_{\mathrm{x}}$ dengan $x=0,3$ nilai magnetisasinya berkurang menjadi 3,28 emu/g. Saat komposisi $x$ ditambah menjadi $x=0,5$ nilai magnetisasinya berkurang lagi menjadi $2,91 \mathrm{emu} / \mathrm{g}$. Pada penambahan komposisi $x=0,7$ nilai magnetisasi berkurang menjadi $1,74 \mathrm{emu} / \mathrm{g}$. 


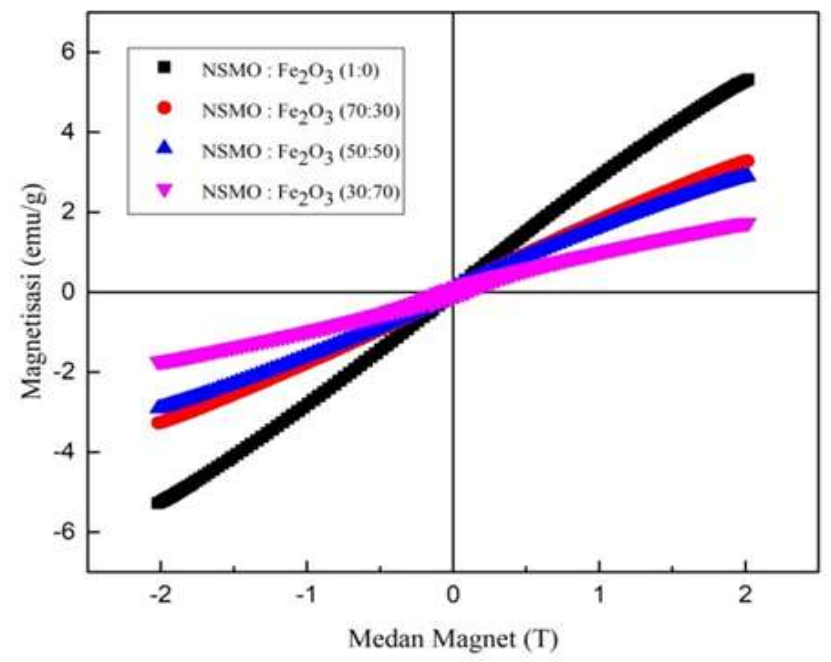

Gambar 6. Grafik magnetisasi terhadap medan magnet pada sampel $(\mathrm{NSMO})_{1-\mathrm{x}} /\left(\mathrm{Fe}_{2} \mathrm{O}_{3}\right)_{\mathrm{x}}(x=0 ; 0,3 ; 0,5 ; 0,7)$ pada temperatur ruang.

Berdasarkan nilai magnetisasi yang diperoleh dapat dilakukan perhitungan dengan menggunakan persamaan (1) untuk mendapatkan nilai susceptibility $(\chi)$, yaitu tingkat kerentanan atau kepekaan suatu material untuk termagnetisasi. Dan didapatkan hasil perhitungan nilai susceptibility $(\chi)$ yang ditampilkan pada Tabel 2.

Tabel 2. Hasil pengujian VSM sampel komposit $\left(\mathrm{Nd}_{0,6} \mathrm{Sr}_{0,4} \mathrm{MnO}_{3}\right)_{1-\mathrm{x}} /\left(\mathrm{Fe}_{2} \mathrm{O}_{3}\right)_{\mathrm{x}}$.

\begin{tabular}{|c|c|c|}
\hline $\begin{array}{c}\text { Konsentrasi } \\
\mathbf{F e}_{2} \mathbf{O}_{3}(\boldsymbol{x})\end{array}$ & $\begin{array}{c}\text { Magnetisasi } \\
(\mathbf{e m u} / \mathbf{g})\end{array}$ & $\begin{array}{c}\text { Susceptibility } \\
(\mathbf{e m u} / \mathbf{g} . \mathbf{T})\end{array}$ \\
\hline 0 & 5,32 & 2,63 \\
\hline 0,3 & 3,28 & 1,63 \\
\hline 0,5 & 2,91 & 1,46 \\
\hline 0,7 & 1,74 & 0,87 \\
\hline
\end{tabular}

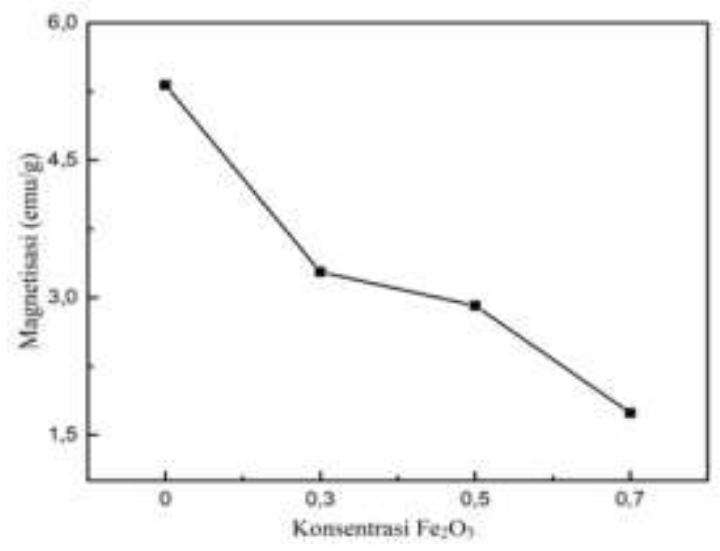

(a)

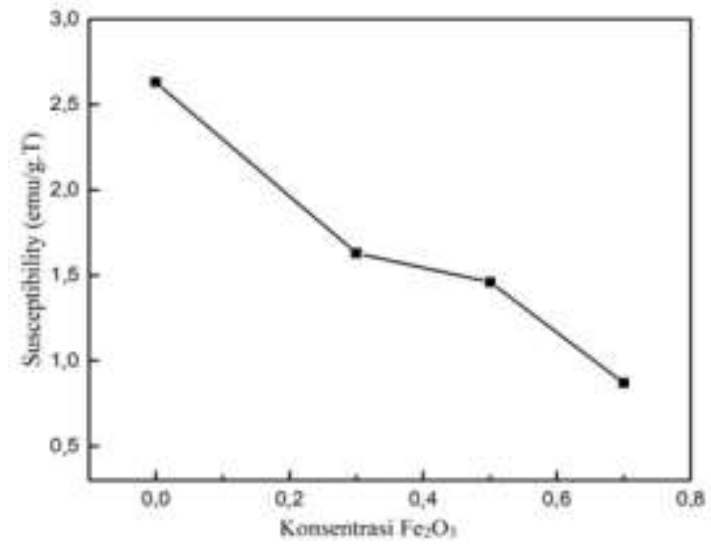

(b)

Gambar 7. (a) Hubungan magnetisasi terhadap konsentrasi $\mathrm{Fe}_{2} \mathrm{O}_{3}$. (b) Hubungan susceptibility terhadap konsentrasi $\mathrm{Fe}_{2} \mathrm{O}_{3}$.

Berdasarkan Gambar 7 (a) dan (b) terlihat bahwa nilai magnetisasi serta susceptibility material $\left(\mathrm{Nd}_{0,6} \mathrm{Sr}_{0,4} \mathrm{MnO}_{3}\right)_{1-\mathrm{x}} /\left(\mathrm{Fe}_{2} \mathrm{O}_{3}\right)_{\mathrm{x}}$ akan semakin menurun seiring dengan penambahan konsentrasi $\mathrm{Fe}_{2} \mathrm{O}_{3}$, karena $\mathrm{Fe}_{2} \mathrm{O}_{3}$ yang dikompositkan, akan menghambat proses double exchange yang terjadi. Dimana menurunnya kemampuan double exchange, akan menyebabkan 
penurunan nilai magnetisasinya [17].

Seperti yang dilaporkan oleh Ahmed dkk [8] dalam penelitiannya mengenai material NSMO yang dikompositkan dengan $\mathrm{CrO}_{3}$, dimana terjadi pergantian ion $\mathrm{Cr}^{3+}$ dengan ion $\mathrm{Mn}^{3+}$ yang melemahkan proses double exchange yang terjadi yang menyebabkan penurunan momen magnetik dan pada akhirnya akan menyebabkan penurunan nilai magnetisasi serta menunjukkan pertambahan nilai resistivitas seiring dengan penambahan $\mathrm{CrO}_{3}$.

Grafik hubungan nilai susceptibility terhadap konsentransi $\mathrm{Fe}_{2} \mathrm{O}_{3}$ yang digunakan, menunjukkan adanya penurunan yang menandakan bahwa tingkat kerentanan atau kepekaan magnetik material $\left(\mathrm{Nd}_{0,6} \mathrm{Sr}_{0,4} \mathrm{MnO}_{3}\right)_{1-\mathrm{x}} /\left(\mathrm{Fe}_{2} \mathrm{O}_{3}\right)_{\mathrm{x}}$ akan semakin rendah seiring dengan penambahan konsentrasi $\mathrm{Fe}_{2} \mathrm{O}_{3}$ yang digunakan.

\section{KESIMPULAN}

Telah berhasil dibuat material komposit $\left(\mathrm{Nd}_{0,6} \mathrm{Sr}_{0,4} \mathrm{MnO}_{3}\right)_{1-\mathrm{x}} /\left(\mathrm{Fe}_{2} \mathrm{O}_{3}\right)_{\mathrm{x}}(x=0 ; 0,3 ; 0,5 ;$ dan $0,7)$ dengan menggunakan metode sol-gel. Refinement hasil pengujian XRD menunjukkan bahwa material $\mathrm{Nd}_{0,6} \mathrm{Sr}_{0,4} \mathrm{MnO}_{3}$ yang telah disintesis memiliki fasa tunggal dan memiliki struktur orthorombik ( $\mathrm{P} \mathrm{n} \mathrm{m} \mathrm{a),} \mathrm{dan} \mathrm{setelah} \mathrm{dikompositkan} \mathrm{dengan} \mathrm{Fe}_{2} \mathrm{O}_{3}$ memiliki dua fasa yang ditandai dengan adanya puncak milik $\mathrm{Fe}_{2} \mathrm{O}_{3}$. Berdasarkan hasil dari pengujian VSM nilai magnetisasi dan susceptibility yang dimiliki material komposit $\left(\mathrm{Nd}_{0,6} \mathrm{Sr}_{0,4} \mathrm{MnO}_{3}\right)_{1-\mathrm{x}} /\left(\mathrm{Fe}_{2} \mathrm{O}_{3}\right)_{\mathrm{x}}(x$ $=0 ; 0,3 ; 0,5 ;$ dan 0,7$)$ mengalami penurunan seiring dengan penambahan $\mathrm{Fe}_{2} \mathrm{O}_{3}$.

\section{REFERENSI}

[1] I. A. Abdel-Latif, "Rare Earth Manganites and their Applications," J. Phys., vol. 1, no. 3, pp. 15-31, 2012.

[2] B. Viswanathan, V. Suryakumar, B. Venugopal, S. H. Roshna, and N. Hariprasad, "Perovskite Materials an Introduction," 2019.

[3] V. R. Sakhalkar, "Structural, Magnetic and Surface Properties Of RF Magnetron Sputtered Undoped Lanthanum Manganite Thin Films," The University Of Texas At Arlington, 2009.

[4] S. O. Manjunatha, A. Rao, T. Lin, C. Chang, and Y. Kuo, "Effect of Ba substitution on structural , electrical and thermal properties of $\mathrm{La0} .65 \mathrm{Ca} 0.35-\mathrm{xBaxMnO} 3(\mathrm{O}<<\mathrm{x}$ $<<0.25$ ) manganites," J. Alloys Compd., vol. 619, pp. 303-310, 2015.

[5] R. K. Nekouei and V. Sahajwalla, "A Green Route to Synthesize Pr3+/Dy3+ -Doped $\mathrm{Nd} 2 \mathrm{O} 3$ Nanoreplicas from Nd-Fe-B Magnets," ACS Sustain. Chem. Eng., 2017.

[6] M. Korotin, "Spin and orbital ordering of Nd1-xSrxMnO3 from LSDA+U calculations," Phys. Rev. B, vol. 59, no. 15, pp. 9903-9910, 1999.

[7] M. Noumi, F. Issaoui, E. Dhahri, and E. K. Hlil, "Study of Critical Behavior and Magnetocaloric Effect in Nd1-xSrxMnO3 Compounds," Jounal Supercond. Nov. Magn., pp. 1507-1516, 2019.

[8] A. M. Ahmed, H. F. Mohamed, A. K. Diab, and S. A. Mohamed, "Synthesis, characterization and low field magnetotransport of $\mathrm{Nd} 0.6 \mathrm{Sr} 0.4 \mathrm{MnO} 3 / \mathrm{CrO} 3$ composite," Indian J Phys, 2016.

[9] B. Balaraju et al., "Structural, Optical and Magnetic Properties of $\alpha$-Fe2O3 Nanoparticles," Jounal Mech. Mater. Eng., pp. 0-5, 2017.

[10] M. A. Islam, "Direc Comparison of the Magnetic Properties of Gd0.7Sr0.3MnO3 Nanoparticles with Bulk Counterparts," University of Engineering \& Technology Dhaka 1000, 2012.

[11] N. Perdrial, "Quantitative X-Ray Diffraction : X'Pert Highscore Plus Rietveld Module," 2010.

[12] J. Setiawan, "Introduction Rietveld Analysis in X'Pert Highscore Plus," no. May, 2018.

[13] G. Venugopal Reddy, P.;Prasad, V.;Venkataiah, "Anomalous variation of magnetoresistance in Nd0.67-y Euy Sr0.33 Mn O3 manganites," Solid State Commun., vol. 141, no. 0, pp. 73-78, 2007. 
[14] E. Handoko, B. Soegijono, and F. R. Tama, Tehnik Difraksi Sinar-X Dalam Analisis Struktur Kristal. .

[15] K. Mader, W.;Kelm, "Synthesis and structural analysis of epsilon-(Fe2 O3)," Zeitschrift fuer Anorg. und Allg. Chemie, vol. 631, no. 0, pp. 2383-2389, 2005.

[16] M. A. Gdaiem, S. Ghodhbane, A. Dhahri, J. Dhahri, and E. K. Hlil, "Effect of cobalt on structural, magnetic and magnetocaloric properties of $\mathrm{La} 0.8 \mathrm{Ba} 0.1 \mathrm{Ca} 0.1 \mathrm{Mn} 1-\mathrm{xCoxO} 3$ ( $\mathrm{x}=0.00,0.05$ and 0.10) manganites," J. Alloys Compd., vol. 3, 2016.

[17] I. N. Rahman, "Pengaruh Substitusi $\mathrm{Cu}$ Terhadap Sifat Kemagnetan dan Kelistrikan Material La0.7(Ba0.97Ca0.03)0.3Mn1-xCuxO3 ( $\mathrm{x}=0 ; 0,03 ; 0,05 ; 0,07$ dan 0,10)," Universitas Indonesia, 2019. 